\title{
How much day surgery? Delphic predictions
}

\author{
John Gabbay, Lesley Francis
}

\begin{abstract}
A list was compiled of 83 of the commonest operations, which according to published reports may be performed on day patients but which in our district were usually performed on inpatients. The results of a national Delphi study among anaesthetists and general surgeons who were known to be in favour of day surgery produced estimates of the probable rates of day surgery for each of those operations under ideal conditions. Comparison of these figures with those from a Delphi study carried out in one district and with figures for day surgery carried out in that district and with waiting list figures enabled two health districts to focus their efforts to increase day surgery.
\end{abstract}

The figures from the national Delphi study could be applied in other districts if the following are taken into account: Hospital Activity Analysis data must be validated; though there was consensus among the national Delphi consultants, personal clinical opinions varied; the case load may grow as waiting lists decrease.

\section{Introduction}

Much has been published on day surgery, and most reports have been in favour of an increase. ${ }^{1.17}$ Nevertheless, fairly little day surgery is carried out. The Royal College of Surgeons has published guidelines and recommendations and discussed the types of operations that are amenable to day surgery. ${ }^{18}$ The estimates of the potential rates for day surgery vary from under one quarter to about half of all surgical cases. ${ }^{918}$ But even when estimates have been based on careful analyses of districts ${ }^{19}$ they have not taken account of the wide variation in rates that is likely among different types of operations. Yet accurate predictions of the potential demand for day surgery are essential for planning district services, particularly as in many regions it is now assumed that future rates of day surgery will be as high as a quarter of all acute admissions now, which is at best a guesstimate.

We present the results of a study to ascertain the maximum potential for day surgery in a specific district, and we discuss how the results may be used in other districts.

\section{Authority}

John Gabbay, MB, senior registrar in community medicine

West Berkshire District Health Authority

Lesley Francis, MSC, statistics and information officer

Correspondence to: Dr John Gabbay, Department of Community Medicine, Parkside District Health Authority, Mint Wing, St Mary's Hospital, Praed Street, London W2 1NY.

We compiled a list of over 250 surgical procedures that were cited in publications as being amenable to day surgery. Many of these are rarely performed, and Hospital Activity Analysis over a 12 month period showed that 83 of the 250 procedures accounted for $95 \%$ of the operations performed in our own district health authority, West Berkshire. We used those 83 operations to conduct a "Delphi study" of a panel of people who were known to be in favour of day surgery in Britain.

A Delphi study is a method of obtaining the collective view of a small group of experts by using repeated rounds of questionnaires and giving anonymous feedback of the responses of colleagues from earlier rounds. ${ }^{20-22}$ The panel consisted of five anaesthetists and six general surgeons, who were expected to consult colleagues about procedures that fell outside their specialised knowledge, such as orthopaedics or ear operations. We expected the Delphi study to indicate the theoretical maximum rates for day surgery as seen by enthusiasts and assuming ideal conditions. Each panellist was sent the list of 83 operations with visual analogue scales on which to estimate the probable percentage of day cases. In the second and third rounds of the study the responses of previous rounds were superimposed, by quartile, on the scale. Thus panellists could if they wished adjust their views in the light of the earlier estimates of their colleagues. In the third and final round of the Delphi study an extra questionnaire was also sent, which asked what overall proportion of patients would be ineligible for day surgery for reasons not directly connected with the operation itself, such as concurrent illness or the physiological, psychological, or social condition of the patient.

The results indicated the maximum potential rates of day cases for each procedure and were then used to analyse the situation in our district in three ways. Firstly, we compared the Delphic potential day surgery rates with the actual rates, which were derived from the most recent 12 months of the local Hospital Activity Analysis validated by a retrospective analysis of operating theatre ledgers from eight randomly sampled weeks. Secondly, we compared the national Delphi study with a local one, which gave the views of surgeons and anaesthetists in our district about possible day surgery rates. The intention was to discover where day surgery rates fell substantially short of the theoretical maximum, what the implications were for the use of inpatient beds, and for which operations would a shift of opinion towards day surgery have the most impact on day surgery in the district. Operations which were performed on relatively higher numbers of patients, required longer lengths of stay, and for which there were greater differences between the results of the national and local Delphi studies were highlighted for special attention.

Thirdly, in another district we applied the Delphic day surgery rates to a waiting list to find out the extent to which increased facilities for day surgery would help surgeons to reduce their lists quickly.

\section{Results}

National Delphi study-Ten of the 11 panellists responded, nine on each of the three rounds. The surgeons tended not to answer questions on specialist operations outside their own field. In each round there was increasing convergence of views about the rates of day surgery that are technically acceptable. Responses to the extra questionnaire yielded a mean estimate that 
$23 \%$ of patients (range $10 \%-50 \%$ ) would be ineligible for day surgery for reasons unconnected with the surgical lesion. The results of the Delphi study (table I) therefore make a total allowance of $25 \%$ as a rounded figure. This allowance includes ineligibility because of age; none of the panel suggested an age limit under 70 years, and five said there should be no limit. There were strong suggestions that age was not relevant, and two panellists argued that day surgery was if anything better than inpatient surgery for old patients as it avoids the risk of disorientation and consequent deterioration that often follows admission to hospital.

Comparison with Hospital Activity Analysis - In West Berkshire (population 437000) there had been just over 1000 instances per average month of the 83 operations on the Delphi list. The Hospital Activity Analysis data for the most recent year were largely confirmed by the operating theatre ledgers. Performing those operations at the rates suggested by the national Delphi panel would have resulted in more than 6500 operations being done as day cases during that year, whereas 3301 were actually recorded as day cases (table II). The operations which were done on inpatients but could probably have been carried out as day surgery accounted for over 5300 bed days.

Comparison with local Delphi study-Table II gives the results of the local Delphi study in which 29 of the
TABLE II - Numbers of operations carried out in one district (Hospital Activity Analysis) and of potential day cases as suggested by local and national Delphic predictions

\begin{tabular}{lccc}
\hline & & \multicolumn{2}{c}{ Delphic predictions } \\
\cline { 3 - 4 } & $\begin{array}{c}\text { Hospital } \\
\text { Activity } \\
\text { Analysis }\end{array}$ & $\begin{array}{c}\text { Local: } \\
\text { West } \\
\text { Berkshire }\end{array}$ & $\begin{array}{c}\text { National }(95 \% \\
\text { confidence intervals) }\end{array}$ \\
\hline Oral & 337 & 397 & $574(540 \cdot 4$ to $607 \cdot 7)$ \\
Thorax & 194 & 162 & $257(226 \cdot 7$ to $287 \cdot 3)$ \\
Ear, nose, and throat & 105 & 491 & $708(595 \cdot 9$ to $820 \cdot 1)$ \\
Abdomen & 478 & 574 & $1079(1015 \cdot 1$ to $1142 \cdot 9)$ \\
Genitourinary & 483 & 844 & $992(966 \cdot 2$ to $1017 \cdot 8)$ \\
Gynaecology & 611 & 1208 & $1508(1484 \cdot 8$ to $1531 \cdot 3)$ \\
Orthopaedics & 193 & 285 & $388(361 \cdot 5$ to $414 \cdot 5)$ \\
Vascular & 343 & 547 & $600(572$ to 628$)$ \\
Eyes & 18 & 102 & $163(133 \cdot 6$ to $192 \cdot 5)$ \\
Other & 67 & 113 & $124(86 \cdot 6$ to $161 \cdot 4)$ \\
\hline- & & & \\
\hline
\end{tabular}

36 local surgeons and anaesthetists participated, 19 participating in all three rounds. The local consultants had a wide range of opinions that narrowed only slightly over the three rounds of the Delphi. They indicated consistently lower proportions of possible day surgery than the national Delphi panel, but they also consistently performed less day surgery than they considered feasible. Age specific data from Hospital Activity Analysis showed that the local policy of a strict age limit of 55 years for day surgery patients

IABLE I-Proportions of operative procedures that could be done as day cases (Delphi results)

\begin{tabular}{|c|c|c|c|c|c|c|c|}
\hline \multirow[b]{2}{*}{ Specialty and operation } & \multirow{2}{*}{$\begin{array}{l}\text { No of } \\
\text { respond- } \\
\text { ents }\end{array}$} & \multicolumn{2}{|c|}{$\begin{array}{l}\text { Percentage } \\
\text { possible as } \\
\text { day cases }\end{array}$} & \multirow[b]{2}{*}{ Specialty and operation } & \multirow{2}{*}{$\begin{array}{l}\text { No of } \\
\text { respond- } \\
\text { ents }\end{array}$} & \multicolumn{2}{|c|}{$\begin{array}{l}\text { Percentage } \\
\text { possible as } \\
\text { day cases }\end{array}$} \\
\hline & & Median & Range & & & Median & Range \\
\hline Eyes & & & & Genitourinary (continued) & & & \\
\hline Resection/shortening of eye muscle & 5 & 25 & $11-33$ & Hydrocelectomy/repair of hydrocoele (adult) & 8 & 55 & $37-71$ \\
\hline Advancement/recession of eye muscle & 5 & 25 & $11-52$ & Orchidopexy (age $0-15$ ) & 7 & 50 & $33-71$ \\
\hline Fxtracapsular extraction of cataract & 4 & 20 & $0-30$ & Orchidopexy (adult) & 8 & 15 & 7.52 \\
\hline Intracapsular excision of cataract & 4 & 5 & $0-11$ & Vasectomy/ligation of vas deferens & 9 & 70 & $60-71$ \\
\hline Ear, nose, and throat & & & & Circumcision (age 0-15) & 9 & 70 & $41-71$ \\
\hline Myringotomy with or without tubes & 7 & 70 & $56-71$ & Circumcision (adult) & 9 & 35 & $15-71$ \\
\hline Tympanoplasty/excision of middle ear lesion & 4 & 0 & $0-0$ & Gynaecology & & & \\
\hline Septal reconstruction/submucal resection & 4 & 15 & $0-30$ & Laparoscopic sterilisation & 7 & 70 & $10-71$ \\
\hline Nasal polyp, removal & 6 & 50 & $30-71$ & Laparoscopic sterilisation-fallopian rings & 6 & 65 & $30-71$ \\
\hline Reduction nasal fracture/zygoma/malar & 5 & 45 & $30-60$ & Polypectomy, cervical & 7 & 70 & $60-71$ \\
\hline Haemangioma, nostril/treat nasal musocal & & & & Dilatation and curettage & 7 & 70 & $60-71$ \\
\hline lesion & 6 & 70 & $60-71$ & Excision lesion of cervix & 7 & 60 & $48-71$ \\
\hline Antral puncture and washouts & 6 & 65 & $51-71$ & Cervical cone biopsy & 7 & 55 & $37-71$ \\
\hline Tonsillectomy, dissection & 5 & 0 & $0-26$ & Intrauterine contraceptive device, removal/ & & & \\
\hline Tonsillectomy, with adenoidectomy & 5 & 0 & $0-52$ & introduction & 7 & 70 & $60-71$ \\
\hline Adenoidectomy & 5 & 25 & $0-52$ & Incision of Bartholin's gland and duct & 7 & 70 & $60-71$ \\
\hline Laryngoscopic procedures & 5 & 55 & $33-37$ & Condylomata acuminata/removal of vulval & & & \\
\hline Teeth, jaws, and mouth & & & & lesions (including Skene's gland) & 7 & 70 & $60-71$ \\
\hline Dental clearance & 6 & 55 & $37-67$ & Abortion, therapeutic & 7 & 70 & $52-71$ \\
\hline Odontectomy, uncomplicated (including & & & & Orthopaedic & & & \\
\hline wisdom teeth) & 6 & 55 & $48-67$ & Removal internal fixation & 7 & 40 & $26-60$ \\
\hline Thorax (including oesuphagus and breast) & & & & Partial ostectomy - for example, exostoses & 6 & 70 & $18-71$ \\
\hline Oesophagoscopy & 8 & 55 & $30-67$ & Metatarsal heads, excision & 6 & 50 & $37-71$ \\
\hline Oesophagoscopy with biopsy & 7 & 45 & $7-52$ & Exostosis, excision & 6 & 55 & $18-71$ \\
\hline Oesophageal dilatation & 8 & 50 & $40-56$ & Arthrotomy & 5 & 45 & $26-60$ \\
\hline Bronchoscopy with biopsy & 7 & 35 & $11-52$ & Arthroscopy/arthrocenteses/arthrography/ & & & \\
\hline Bronchoscopy & 7 & 55 & $37-67$ & therapeutic injection & 7 & 65 & $60-71$ \\
\hline Breast masses, excision (including, for & & & & Manipulation of joints (with or without $x$ ray) & 7 & 70 & $48-71$ \\
\hline example, gynaecomasti & 9 & 60 & $40-71$ & Arthrodesis phalanges/other joints & 7 & 40 & $26-71$ \\
\hline Abdomen & & & & Arthroplasty (foot/hand) & 5 & 25 & $26-33$ \\
\hline Paracentesis & 7 & 55 & 33.60 & Meniscectomy & 4 & 50 & $0-63$ \\
\hline Laparoscopy & 9 & 55 & $40-71$ & Extirpation of other joint structures & 5 & 10 & $0-15$ \\
\hline 1 (age $0-15$ unilateral) & 9 & 70 & $52-71$ & Excision of Baker's cyst and other joint & & & \\
\hline $\begin{array}{l}\text { Herniorrhaphy, inguinal (adult-unilateral) } \\
\text {. }\end{array}$ & 9 & 55 & $30-71$ & structures & 6 & 35 & 3.52 \\
\hline uinal (age $0-15$ bilateral) & 9 & 60 & $52-71$ & Trigger finger re & 7 & 70 & $60-71$ \\
\hline uinal (adult-bilateral) & 9 & 55 & $0-71$ & Ganglionectomy/removal tendon lesions & 7 & 70 & $63-71$ \\
\hline Herniorrhaphy, & 9 & 70 & $48-71$ & Tendon repair & 7 & 15 & $11-48$ \\
\hline Herniorrhaphy, umbilical (adult) & 9 & 40 & $18-71$ & Fasciotomy (finger, palm) & 7 & 70 & $37-67$ \\
\hline Gastroscopy/biopsy of stomach, duodenum, & & & & Carpal/tarsal tunnel decompression & 7 & 70 & $60-71$ \\
\hline & 9 & 55 & $37-71$ & Vascular/skin & & & \\
\hline Colonoscopy/sigmoidoscopy & 9 & 70 & $60-71$ & Varicose vein ligation & 9 & 70 & $48-71$ \\
\hline Endoscopy & 9 & 70 & $60-71$ & sion/stripping & 8 & 55 & $18-60$ \\
\hline Pilonidal cystectomy & 9 & 50 & $11-71$ & Lymph node biopsy & 7 & 65 & $60-71$ \\
\hline Incision of fistula/division of anal sphincter & 9 & 40 & $26-71$ & Excision/destruction of lipoma/superficial cyst & & & \\
\hline Anal dilatation & 9 & 70 & $37-71$ & or fistula/skin tags, skin lesions (excluding & & & \\
\hline Haemorrhoidectomy (excision) & 9 & 15 & $0-41$ & wide excisions) & 9 & 70 & $56-71$ \\
\hline Liver biopsy, needle & 8 & 55 & $7-67$ & Excision of other lesions of skin or & & & \\
\hline Genitourinary & & & & subcutaneous tissue & 9 & 70 & $60-71$ \\
\hline Renal biopsy, percutaneous & 6 & 40 & $0-67$ & Fingernail or toenail removal & 9 & 70 & $60-71$ \\
\hline py and destroy lesion & 8 & 60 & $37-71$ & Wart ligation and other minor skin procedures & 9 & 70 & $60-71$ \\
\hline Cystoscopy & 8 & 70 & $60-71$ & Other procedures & & & \\
\hline Division/excision of unrethral stricture & 8 & 25 & $7-60$ & Injection of intervertebral disc/spinal puncture & & & \\
\hline Orchidectomy - unilateral or partial & 8 & 40 & $7-71$ & & 5 & 40 & $18-67$ \\
\hline Hydrocelectomy/repair of hydrocoele (age & & & & Examination under anaesthesia & 6 & 70 & 63-71 \\
\hline $0-15)$ & 8 & 70 & $52-71$ & & & & \\
\hline
\end{tabular}


contributed substantially to the shortfall of low day surgery rates compared with the rates suggested by the national Delphi study. The results of the local study showed, however, that clinical opinion and limited facilities were also important factors.

Comparing the two sets of Delphic results operation by operation with the validated Hospital Activity Analysis showed that any substantial increase in day surgery in West Berkshire would chiefly depend on appreciable changes in day case rates for about 30 of the operations. This meant that doctors, planners, and managers needed to focus on the clinical attitudes, practices, and facilities for those operations if appreciable increases in rates for day surgery were to be achieved.

Other applications-We were able subsequently to apply the national Delphic results in another district to show that a reduction of nearly 2000 bed days a year could be achieved on the orthopaedic wards if the median Delphic day surgery rates were applied to the nearly 4000 orthopaedic inpatients who were treated there in 1985. That district, which undertakes little orthopaedic day surgery, has 810 orthopaedic patients on the waiting list for inpatient beds. According to the national Delphic criteria 470 of them could be dealt with as day cases.

\section{Discussion}

The national Delphi study gave detailed estimates of potential rates of day surgery for operations that are commonly performed on inpatients in our district. These estimates were much higher than the estimates of the consultants in the local Delphi study, which were in turn higher than the rates of day surgery performed. The detailed figures for our district are being used to plan to develop the service. The figures from the national Delphi study may be similarly used by other districts or regions where there is a desire to realise the full poential of day surgery.

Several points need to be considered, however, when undertaking such a study. Firstly, local Hospital Activity Analysis data may be unreliable, and a validation, such as the analysis of the sample of theatre ledgers provided, is mandatory. Furthermore, operations may not always be coded so that potential day surgical procedures can be identified separately, though this is unlikely to affect the calculations greatly.

Secondly, the generalisability of the national Delphi: although by the third round of the Delphi there was a notable consensus among the members of the national panel inevitable differences in general clinical opinion means that only a proportion of consultants will accept that day surgery should be practised as widely as the figures suggest. Moreover, surgeons on the panel did not respond to questions on subspecialisms such as ear, nose, and throat surgery and orthopaedics, where the result may therefore be less reliable.

Thirdly, by increasing throughput of patients day surgery may lead to additional activity that satisfies a previously unmet need. An increase in day surgery can thus reduce waiting lists dramatically without relieving the inpatient wards of their normal case loads. This plus the tendency to use day surgery facilities for operations that could otherwise be done on outpatients -for example, colonoscopies, minor lumps, and varicose vein injections - can lead to a large workload, which is not a substitute for inpatient surgery but is additional. As day surgery becomes established in a district its popularity grows rapidly - a snowball effect (T Ogg and P Jarrett, personal communications). The additional, though not the substitute, demand may diminish once long waiting lists have been dealt with (J Calnan, personal communication).
Fourthly, we had to make several assumptions when using the Delphic figures: that $25 \%$ of patients would be ineligible for reasons other than the nature of the surgical lesion; that the age distribution for each operation would remain unchanged when day surgery increased; that operations that were not among the 83 on the Delphic list would account for $3 \%$ of total day surgery; and that no patients undergoing such surgery would already be in hospital for other reasons. Furthermore, these figures do not include day patients, from whatever specialty, who do not have operations, which routine returns ( $\mathrm{SH} 3$ ) suggest would add between $1 \%$ and $2 \%$ to our estimate.

Finally, the figures assume that the facilities are good, well organised, and well managed - an essential prerequisite for a successful service. Clearly, predictions based on our figures must be critically scrutinised, but they may nevertheless throw some light on local debates about feasible rates of day surgery.

If day surgery is as acceptable to patients and staff as has been reported ${ }^{23.32}$ (and coincidentally by the recent personal experiences of both of us as day patients for operations on the Delphic list), if it increases efficiency, ${ }^{3346}$ and above all if it is as safe and effective as inpatient surgery ${ }^{47.53}$ then there is a strong case for doing more-even if the consequent savings in resources may well be small. ${ }^{54}$ Evaluations of the outcome of day surgery are still needed, however.

Our method has helped to predict the scope for increased day surgery in two districts and can be applied elsewhere. Our findings highlight which operations might be considered for day surgery if changes in facilities and attitudes come about in response to recommendations for an increase from the Department of Health and Social Security, regions, and the Royal College of Surgeons.

We thank Dr M Roach, Ms C Moore, and Ms C Birch for help with the research and the members of both Delphi panels for their invaluable contribution. The 10 nationwide Delphi panellists were: Dr E N Armitage, Dr J Burn, Professor J Calnan, Dr H T Davenport, Mr H B Devlin, Professor H A F Dudley, Mr P Jarrett, Dr B Kay, Dr T Ogg, and Mr C V Ruckley.

I Calnan J, Martin P. Development and practice of an autonomous minor surgery unit in a general hospital. BrMed $\mathcal{O} 1971$;iv:92-6.

2 Atwell JD, Burn JMB, Dewar AK, Freeman NV. Paediatric day-case surgery. Lancet 1973;ii:895-7.

3 Anonymous. Tottering home [Editorial]. Lancet 1975;i:1366-7.

4 O'Donovan TR. The dynamics of ambulatory surgery. Hospital Administration 1975;20:27-39.

5 Simpson JEP. Day care surgery. Br $\mathcal{F}$ Hosp Med 1976;16:571-8.

6 Boardman KP, Griffiths JC. Elective out-patient surgery in orthopaedics. Health Trends 1977;9:9-11.

7 Health Services Directorate. Day surgery unit-guidelines. Ottawa, Ontario Minister of National Welfare and Health, 1978.

8 Burn JMB. A blueprint for day surgery. Anaesthesia 1979;34:799-805.

9 Oosterlee J, Dudley HAF. Surgery in outpatients. Br Med J 1979;ii: 1459.

$10 \mathrm{Ogg} \mathrm{TW}$. Use of anaesthesia. Implications of day-case surgery and anaesthesia. BrMed f 1980;281:212-4.

11 Detmer DE. Ambulatory surgery. $N$ Engl F Med 1981;305: 1406-9.

12 Ruckley CV, Ferguson JBP, Cuthbertson C. A five-day ward as part of a comprehensive surgical service. Br Med f 1981:282:1525-8.

13 Ruckley CV, Ferguson JPB, Cuthbertson C. Surgical decision making. $\mathrm{Br} \mathcal{J}$ Surg 1981;68:837-9.

14 Jarrett P. Sameday progression. Nursing Mirror 1982;154:32-4

15 Haines JF, Thompson H. Short-stay surgery in orthopaedics. Health Trends 1982;14:73-4.

16 Quill DS, Devlin H, Plant JA, et al. Surgical operation rates: a twelve year experience in Stockton-on-Tees. Ann R Coll Surg Engl 1983;65:248-53.

17 Lord PH. Pros and cons of day case surgery. Br $\mathcal{F}$ Hosp Med 1984;32:161.

18 Commission on the Provision of Surgical Services. Guidelines for day case surgery. London: Royal College of Surgeons of England, 1985.

19 Cliff KS. The use of hospital activity analysis data in assessing operative procedures suitable for five-day care. Health and Social Services fournal 1979;89:A29-32.

20 Pill J. The Delphi method: substance, context, a critique and an annotated bibliography. Socio-Economic Planning Science 1971;5:57-71.

21 Milholland AV, Wheeler SG, Heieck. JJ. Medical assessment by a Delphi group opinion technic. N Engl I Med 1973:288:1272-5.

22 Chariton JRH, Patrick DL, Matthews G, West PA. Spending priorities in Kent: a Delphi study. I Epidemiol Community Health 1981;35:288-92.

Kent: a Delphi study. F E pidemiol Community Health 1981;35:288-92.
23 Shah CP, Robinson GC, Davenport HT. Day care surgery for children: Shah CP, Robinson GC, Davenport HT. Day care surgery for children: a
controlled study of medical complications and parental attitudes. Med Care

24 Steward DJ. Experiences with outpatient anaesthesia service for children. Anesth Analg 1973;52:877-80. 
25 Armitage EN, Howat JM, Long JW. A day-surgery programme for children incorporating anaesthetic outpatient clinic. Lancet 1975;ii:21-3.

26 Clyne CAC, Jamieson CW. The patient's opinion of day care vein surgery. $\mathrm{Br} \mathcal{F}$ Surg 1978;65:194-6.

27 Garraway WM, Cuthbertson C, Fenwick N, Ruckley CV, Prescott RJ. Consumer acceptability of day care after operations for hernia or varicose veins. I Epidemiol Community Health 1978;32:219-21.

28 Pineault $R$, Contandriopoulos A-P, Valois M, Bastian M-L, Lance J-M. Randomized clinical trial of one-day surgery: patient satisfaction, clinical Randomized clicsts. Med Care 1985;23:171-82.

29 Ruckley CV, Garraway WM, Cuthbertson C, Fenwick N, Prescott RJ. The community nurse and day surgery. Nursing Times $1980 \mathrm{Feb} 7: 255-6$.

30 Anonymous. Day care surgery [Editorial]. I $R$ Coll Gen Pract 1980;30:2-3.

31 Hart C. Back home to nurse. Nursing Mirror 1982;154:ii-vii.

32 Garraway WM, Ruckley CV, Prescott RJ. General practitioners' response to day care surgery. Practitioner 1978;221:22-5.

33 Draper P. Cutting the cost of health care. Lancet 1970;ii:601.

34 Hawthorne DD. Hospital-based unit improves utilization. Hospitals 1975;49: 62-5.

35 DHSS. Out patient arrangements: one day minor surgery unit. London: HMSO, 1977. (Abstracts of efficiency studies in the National Health Service: No 179.)

36 Bourke JB, Balfour TW, Finlay SE. The use and value of a university health centre with attached beds in the management of general surgical patients. Health Trends 1978;10:42-4.

37 Prescott RJ, Cuthbertson C, Fenwick N, Garraway WM, Ruckley CV. Economic aspects of day care after operations for hernia or varicose veins. $f$ Epidemiol Community Health 1978; 3:221-5.

38 Catford J, Fowkes FGR. Economic benefits of day care abortion. Community Med 1979;1:115-22.

39 Grossman RM. Is ambulatory surgery less expensive? Hospitals 1979;53:112-6.

49 Grossman RM. Is ambulatory surgery less expensive? Hospitals 1979;53:112-6. Barker

41 Lairson DR, Baron AE, Swint JM, Greenlick MR, Marks SD. Do-not-admit versus inpatient surgery in an HMO: determinants of choice and the implications for medical care costs. Health Serv Res 1980;15:378-96.

42 Evans RG, Robinson GC. Surgical day care: measurements of the economic payoff. Can Med Assoc F 1980;123:873-80.

43 Marks SD, Greenlick MR, Hurtado AV, Johnson JD, Henderson J. Ambulatory surgery in an HMO: a study of costs, quality of care and satisfaction. Med Care 1980;18:127-46.

44 West RR, McKibbin B. Shortening waiting lists in orthopaedic surgery outpatient clinics. Br Med F 1982;284:728-30.

45 Karpman S. Day surgery versus inpatient surgery: a cost comparison. Health Management Forum 1983;4:54-63.

46 Burn JMB. Responsible use of resources: day surgery. Br Med f 1983;286: 492-3.

47 Ruckley CV, Maclean M, Ludgate CM, Espley AJ. Major outpatient surgery. Lancet 1973;ii:1193-6.

48 Blodgett JB, Beattie EJ. Early post operative nursing: a statistical study of hospital complications. Surg Gynecol Obstet 1975;20:27-39.

49 Devlin HB, Russell IT, Muller D, Sahay AK. Short-stay surgery for inguina hernia: clinical outcome of the Shouldice operation. Lancet 1977;i:844-7.

50 Russell IT, Devlin HB, Fell M, Glass NJ. Day-case surgery for hernias an haemorrhoids: a clinical, social and economic evaluation. Lancet 1977; 844-7.

51 Adler MW, Waller JJ, Creese A, Thorne SC. Randomized controlled trial of early discharge for inguinal hernia and varicose veins. 7 Epidemio Community Health 1978;32:136-42.

52 Goulbourne IA, Ruckley CV. Operations for hernia and varicose veins in a daybed unit. Br Med 7 1979;ii:712-4.

53 Collins KM, Docherty PW, Plantevin OM. Perioperative morbidity followin gynaecological out-patient laporoscopy-a reappraisal of the service. gynaecological out-patient
Anaesthesia $1984 ; 39: 819-22$.

54 Allen NJ. The scope and benefit of day surgery in Southampton. Bath: University of Bath, 1986. (MPhil thesis.)

(Accepted 16 August 1988)
University Rehabilitation

Unit, Southampton General Hospital, Southampton SO9 4XY

Kevin J Walsh, MRCP, lecturer in disability medicine Michael P Barnes, MRCP, lecturer in disability medicine D Lindsay McLellan, FRCP, professor of rehabilitation

Correspondence to:

Professor McLellan.

\title{
A rehabilitation ward in a district general hospital: first three years' experience
}

\author{
Kevin J Walsh, Michael P Barnes, D Lindsay McLellan
}

\begin{abstract}
The experience of the first three years' work on a ward for the rehabilitation of patients was reviewed. Adults with physical disabilities or mixed physical and psychological disabilities, including unstable or deteriorating conditions, were accepted for intensive rehabilitation. Most patients had neurological disorders. The ward policy was that each patient had considerable time with the therapist, maximum personal independence was encouraged, and multidisciplinary staff meetings were held to agree the goals of treatment.

Much effort was spent helping patients and relatives to adapt to conditions of progressive disability, but the response to questionnaires suggested that these patients as well as those who did improve received some benefit from being on the ward. Overall the benefits of the intensive rehabilitation that was offered on this ward outweighed those from short stays on medical wards.
\end{abstract}

\section{Introduction}

It is the policy of the Royal College of Physicians that rehabilitation should be a natural part of the work of every clinician, but it is also recognised that certain patients have disabilities that are so complex or unusual that they require special skills and facilities for their management, sometimes including specialist inpatient care. ${ }^{1}$ We describe the experience on a ward designated for the management of patients with severe disability during the first three years of its existence.

The ward-The ward is in a large district general and teaching hospital serving a health district of 410000 people. The hospital site includes regional facilities for neurology, neurosurgery, and cardiothoracic surgery; burns and spinal injury units and the artificial limb and appliance centre are sited elsewhere. The ward is on the fifth floor and comprises two six bedded bays and two single rooms and shares some facilities with the adjacent rheumatology ward. The plan of the ward is identical with that of others in the block used for acute medical and surgical services, and there have been few modifications to cater for its special functions. An empty bay was modified into a day room, but there is still inadequate space for staff clerical tasks and for private interviewing. The main physiotherapy and occupational therapy treatment areas and a large aid and equipment centre are on the ground floor, accessible by lifts and corridors. An information service ("Help for Health") and a heavy workshop are available, but there are no industrial training facilities. Eight beds in the ward were opened in March 1984, and a further six in June 1985.

Staff-The consultant staff initially comprised the professor of rehabilitation (a neurologist) and a senior lecturer in rehabilitation with a special interest in rheumatology. A second senior lecturer, also a neurologist, took up his post in January 1986. Junior medical staff include a lecturer (registrar) and a senior house officer and preregistration house officer who are shared with the department of rheumatology. Seven whole time equivalent qualified nurses and two auxiliary nurses are supervised by a full time ward sister. Two physiotherapists and one occupational therapist have a full time commitment to the ward. (For comparison the 172 general medical beds in the hospital are served by four physiotherapists and 1.5 whole time equivalent occupational therapists, 112 geriatric beds by two physiotherapists and 2.3 whole time equivalent occupational therapists, and 75 neurological and neurosurgical beds by three physiotherapists, occupational therapy being provided by referral only.) A speech therapist, a clinical psychologist, an activities organiser, and two hospital based social workers (employed by the local authority social services department) have a half time commitment to the ward. There are also electronic and mechanical engineering technicians available.

Functions of the ward-The principal purpose of the 